National Marine

Fisheries Service

NOAA
Fishery Bulletin

a established in 1881 a
Spencer F. Baird

First U.S. Commissione of Fisheries and founder of Fishery Bulletin

\begin{abstract}
Bottom trawl surveys need constant catchability over time to produce estimates of relative abundance that are most informative for stock assessment modeling. However, environmental conditions during surveys can potentially produce both interannual and long-term changes in catchability. Here we consider the effects of one environmental variable, sea state, on vessel motion, trawl performance, and, presumably, catchability. We present the results of 2 field experiments performed on chartered commercial trawlers typical of those used by the National Marine Fisheries Service for conducting its eastern Bering Sea bottom trawl survey. The first experiment shows that wave-induced vessel motion is transmitted down the towing warps, creating vertical oscillation in both trawl bridles and the footrope, which potentially influence both the herding and footrope escapement of fish. The second experiment shows that the herding of yellowfin sole (Limanda aspera) by the survey trawl decreases with an increase in wave height. A proposed mathematical model of flatfish herding is used to provide a hypothetical mechanism describing the effect of surface waves on flatfish herding. In addition, the annual biomass estimates of yellowfin sole determined from the bottom trawl survey data are shown to decrease with increasing wave height. The potential impacts of these relationships on the yellowfin sole assessment model are then considered.
\end{abstract}

Manuscript submitted 9 May 2017. Manuscript accepted 18 October 2017. Fish. Bull. 116:21-33 (2018).

Online publication date: 9 November 2017. doi: $10.7755 / F B .116 .1 .3$

The views and opinions expressed or implied in this article are those of the author (or authors) and do not necessarily reflect the position of the National Marine Fisheries Service, NOAA.

\title{
The effects of wave-induced vessel motion on the geometry of a bottom survey trawl and the herding of yellowfin sole (Limanda aspera)
}

\author{
David Somerton (contact author) \\ Kenneth Weinberg \\ Peter Munro \\ Louis Rugolo \\ Thomas Wilderbuer \\ Email address for contact author: dsomerton4@gmail.com \\ Resource Assessment and Conservation Engineering Division \\ Alaska Fisheries Science Center \\ National Marine Fisheries Service, NOAA \\ 7600 Sand Point Way NE, Building 4 \\ Seattle, Washington 98115-6349
}

Uncertainty in estimates of relative stock abundance determined from bottom trawl survey data has long been recognized to be a function of sample size, survey design, and species patchiness (Kimura and Somerton, 2006). However, the relative-abundance estimate at each sampling location depends on trawl sampling efficiency (i.e., the proportion of animals that are captured within the trawl path); consequently, uncertainty in surveywide estimates of relative abundance must also reflect spatial and temporal variability in sampling efficiency. Despite efforts to reduce the influence of this variability on NOAA bottom trawl surveys through the standardization of survey gear and operational protocols (Stauffer, 2004), biotic and abiotic factors remain that cannot be controlled. We examined the influence of one such factor: that is, surface waves, which affect, in turn, vessel motion, trawl geometry, and sampling efficiency (Politis et al., 2012). Here we consider the effects of wave height on the performance of the bottom trawl used by the Alaska Fisheries Science Center, National
Marine Fisheries Service, to conduct its annual eastern Bering Sea (EBS) trawl survey (henceforth referred to as "the survey trawl"; Conner and Lauth, 2016).

Although the connection between surface waves and vessel motion is readily apparent, the connection between vessel motion and trawl performance is not. Previous studies, however, have shown that effects of vessel motion can be pronounced. For example, O'Neill et al. (2003) considered the increase in size selectivity observed by trawl fishermen during stormy periods, focused on the oscillation in trawl speed caused by vessel motion, and investigated its consequent effects on the opening of codend meshes and fish escapement. Likewise, Politis et al. (2012) examined how vessel motion can be transmitted down the towing warps to impact many aspects of trawl performance, especially bottom contact of the trawl bridles (which influences fish herding) and bottom contact of the footrope (which influences fish escapement) (Dickson, 1993; Somerton et al., 2007). 
In this study, we consider several related topics connected to the potential effects of surface waves on sampling efficiency of the survey trawl. First, we describe a field experiment that we conducted, which was similar to those of O'Neill et al. (2003) and Politis et al. (2012), to estimate the effects of vessel motion on the bottom contact of the bridles and footrope of the survey trawl. Second, we describe another field experiment that we conducted to estimate the effects of wave height on the herding of yellowfin sole (Limanda aspera). The experimental design focused on the trawl bridles, which has been shown to be the primary trawl component determining sampling efficiency of flatfishes (Somerton and Munro, 2001; Munro and Somerton, 2002). Third, we use the results of these 2 experiments to develop a mathematical model describing the effect of wave height on the herding of yellowfin sole. Fourth, we examine how the annual biomass estimates of yellowfin sole determined from EBS trawl survey data, and the deviations between these estimates and those produced by the yellowfin sole stock assessment model (Wilderbuer et al. ${ }^{1}$ ), are correlated with wave heights that the vessels encountered during the surveys. Finally, we consider the significance of these findings in terms of fisheries stock assessments.

\section{Materials and methods}

\section{Description of the EBS survey trawl}

The EBS survey trawl, known as the 83-112 Eastern trawl, is a low-rise, 2-seam flatfish trawl designed for use on a smooth, soft sea bottom. A detailed description is of its design and construction is presented in Stauffer (2004), however several aspects of its design are important for this study and are considered below (Fig. 1). The nylon net has a $25.5-\mathrm{m}$ headrope and 34.1$\mathrm{m}$ footrope which is $5.2 \mathrm{~cm}$ in diameter and constructed of wire rope with a single wrap of both polypropylene line and split rubber hose, but without bobbins or rollers to allow it to better conform to the smooth bottom in the EBS. The net is attached to a pair of $55-\mathrm{m}$ wire bridles that are joined together and attached to a single 12.2-m wire door leg extension, which, in turn, is connected to two, 3-m chain door legs attached to 816$\mathrm{kg}$ steel "V" doors (Fig. 1). Although this length of door leg extension is typical for many EBS survey vessels, door legs are custom built for each charter vessel and can vary from 8 to $15 \mathrm{~m}$. Henceforth, when bridle measurements are specified aft of the doors, they include the length of the door extension for a specific vessel

\footnotetext{
${ }^{1}$ Wilderbuer, T. K., D. G. Nichol, and J. Ianelli. 2015. Assessment of the yellowfin sole stock in the Bering Sea and Aleutian Islands. In Stock assessment and fishery evaluation report for the groundfish resources of the Bering Sea/ Aleutian Islands regions, p. 733-820. North Pacific Fishery Management Council, Anchorage, AK. [Available from website.]
}

but exclude the lengths of the tail chains, which are standard for all vessels.

\section{Wave height and vessel motion}

Experimental design An experiment to estimate the performance of the survey trawl at various levels of wave height was conducted in the EBS from 14 through 25 September 2003 aboard the chartered $38-\mathrm{m}$ commercial stern trawler FV Vesteraalen. Because wave heights cannot be predicted sufficiently far in advance to plan a study of wave height, the experimental tows were completed opportunistically, in 2 parts, while the vessel was engaged in other studies. The first part, located near $55^{\circ} 58^{\prime} \mathrm{N}, 162^{\circ} 55^{\prime} \mathrm{W}$ at a depth of $82 \mathrm{~m}$, consisted of repetitive trawl tows that were $5 \mathrm{~min}$ in duration, measured from the time the trawl first contacted the bottom to the time the footrope left the bottom by using a bottom contact sensor (BCS; Weinberg and Somerton, 2006). The second part, located near $55^{\circ} 10^{\prime} \mathrm{N}, 166^{\circ} 15^{\prime} \mathrm{W}$ at a depth of $115 \mathrm{~m}$, consisted of repetitive tows that were $15 \mathrm{~min}$ in duration. During both parts, all operating procedures, except tow duration (standard survey tow duration is $30 \mathrm{~min}$ ) and the use of open codends, were consistent with EBS trawl survey sampling protocols (Stauffer, 2004).

Various aspects of trawl geometry were measured on all tows. Along the footrope, the distance between the footrope and the seafloor (off-bottom distance) was measured to the nearest centimeter, at 1.5-s intervals and at 5 positions by placing BCS units at the center of the footrope, at $3 \mathrm{~m}$ to both sides of the center (the footrope corners), and on each wing $1 \mathrm{~m}$ behind the wing tip (Fig. 1). Along the bridles, off-bottom distance was measured at 6 positions by placing BCS units on the lower bridle at distances of 25,40 , and $50 \mathrm{~m}$ forward of the wing tip on both port and starboard sides of the trawl (Fig 1; measurements were made at all 11 positions simultaneously). The BCS units measure the tilt angle between their points of bottom contact and their points of attachment to the trawl and were individually calibrated to allow prediction of off-bottom distance from tilt angle. Description of the BCS units and the methods for attaching them to the footrope and bridles are described in Weinberg and Somerton (2006).

Heave (vertical movement in centimeters), pitch (angular motion on the along-vessel axis to the nearest $0.1^{\circ}$ ), and roll (angular motion on the across vessel axis to the nearest $0.1^{\circ}$ ) were measured with a heave, pitch, and roll sensor (Teledyne TSS Ltd., ${ }^{2}$ Watford, UK) at 1-s intervals. The sensor, which was positioned near the center of motion of the vessel, allowed prediction of heave at one remote position on the vessel based on the $\mathrm{x}, \mathrm{y}$, and $\mathrm{z}$ coordinates of this position in relation to the sensor. We chose this position as the location where the starboard warp passed over the stern trawl

\footnotetext{
2 Mention of trade names or commercial companies is for identification purposes only and does not imply endorsement by the National Marine Fisheries Service, NOAA.
} 


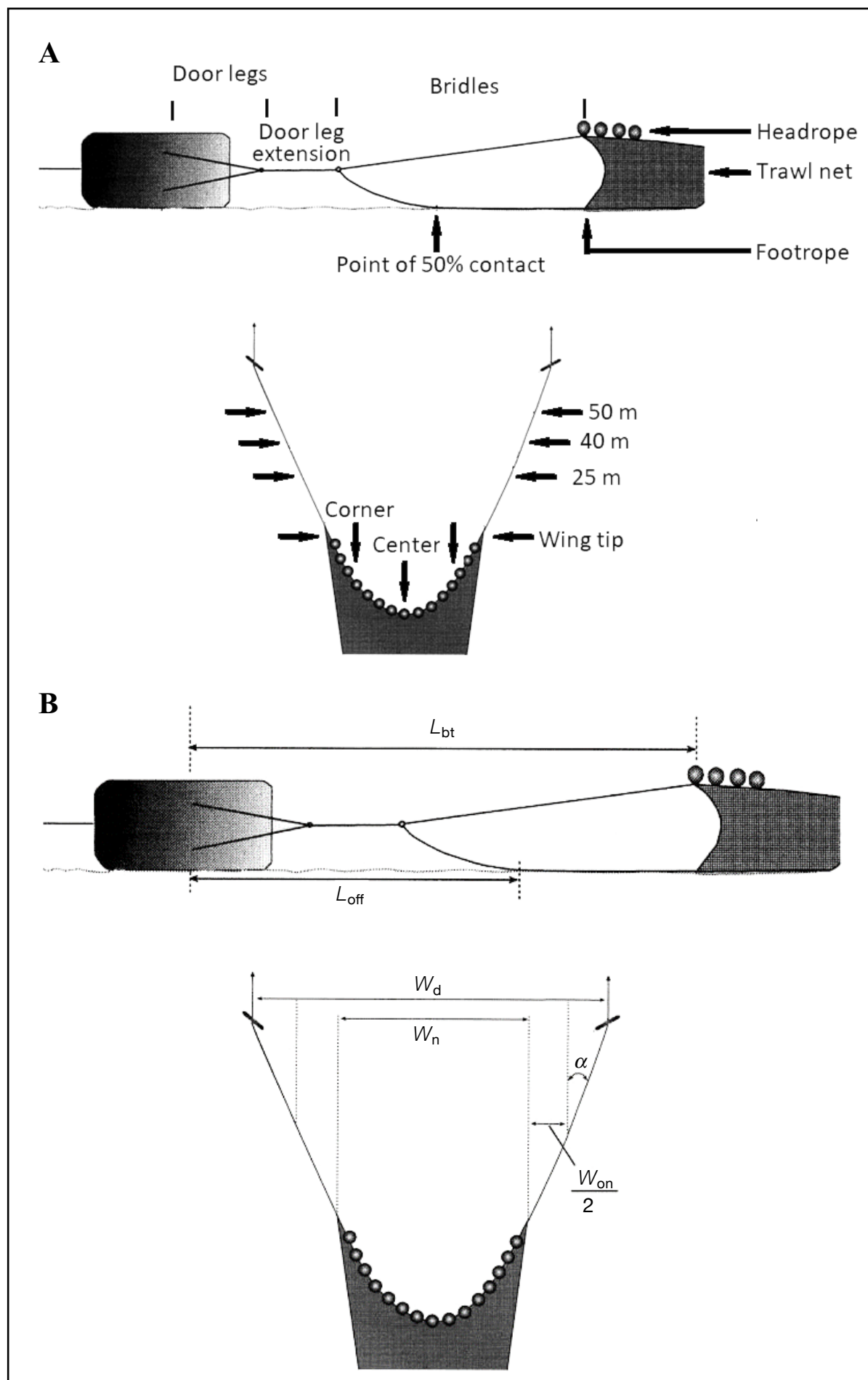

Figure 1

(A) Schematic diagram of the 83-112 Eastern survey trawl used in an experiment conducted in the eastern Bering Sea during September 2003, shown from the side (upper diagram) and from above (lower diagram). Various trawl components referred to in the text are identified in the upper diagram. Placement locations of bottom contact sensors along the lower bridles and footrope are indicated by arrows in the lower diagram. (B) Diagram showing the trawl dimension variables used in the catch ratio model to describe how wave height can influence herding of yellowfin sole (Limanda aspera). 
block (i.e., the last point of contact between the vessel and the warp) and measured its coordinates relative to the heave sensor with a surveyor's tape. In addition, 2 measures of sea state, swell height and wave height, were estimated by the vessel captain during each tow. Recognizing that these are subjective estimates, we did not try to disentangle the exact meanings of the 2 values, but instead followed the approach of Stewart et al. (2010) and simply added them together to create a composite value of sea state, henceforth referred to as wave height. In addition, the captain estimated the wave direction and determined the angular difference between wave direction and vessel heading. This directional difference was recorded both as a numeric value (i.e., the absolute value of the cosine of the angle between the 2 directions) and as a relative value (i.e., the vessel heading either toward or away from the wave direction).

Analysis of wave height, vessel motion, and trawl motion data The data for each tow consisted of 1) wave height and the difference between wave direction and vessel heading, 2) remote heave at the trawl block, and 3) offbottom distances at each of the 11 positions along the lower bridles and footrope. Mean and standard deviation of the heave and off-bottom measurements were computed for each of the 62 tows but the number of off-bottom values varied among the measurement positions because of occasional malfunction of some BCS units. Henceforth, the standard deviation of the heave at the trawl block (SDH) will be used as a measure of vessel motion.

We examined whether SDH is influenced by variables other than wave height, in particular, the numeric and relative differences between vessel heading and the wave direction, by including both variables, along with wave height, in a linear model (using the function $\mathrm{lm}$ in R, vers. 2.0.0; R Development Core Team, 2004) of SDH. Analysis of variance was used to test for the significance of the terms. Nonsignificant variables were removed and the model was re-fit sequentially until all remaining variables were significant. In addition, we used linear models to examine whether the mean and standard deviation of off-bottom measurements at each BCS position were influenced by SDH, using analysis of variance to test the significance of $\mathrm{SDH}$.

Because the driving variable for movement of the vessel, and potentially the trawl, was surface waves, the time series of vertical measurements from each trawl location can display periodic oscillations. As did O'Neill et al. (2003) and Politis et al. (2012), we assumed that coherence in the period of oscillations between the vessel and the various measurement locations on the trawl indicated that surface waves were the causative agent of trawl motion. Therefore, for some tows, measurements of heave and off-bottom distance were subjected to spectral analysis (spectrum function in statistical software $\mathrm{S}+$, vers. 6.2, TIBCO Software, Inc., Palo Alto, CA; Venables and Ripley, 1994) to determine the major period of oscillation. The period was estimated as the inverse of the frequency at the spectral peak, multiplied by the sampling interval (the sampling interval differed among the various types of data).

\section{Wave height and herding of yellowfin sole}

Experimental design Flatfish are typically herded into the net path by direct contact with or close approach of the lower bridles. The proportion of the fish within the bridle contact area (i.e., area of the bottom contacted by the bridles) that are herded into the net path can be determined by using a herding experiment (Engås and Godø,1989) in which the size of the bridle contact area is varied by repeatedly conducting trawl hauls with varying bridle lengths. In previous experiments with a survey trawl, this species was strongly herded $(\sim 60 \%$ of fish within the contact area were herded into the trawl path; Somerton and Munro, 2001), therefore yellowfin sole was considered a good candidate species for examining the influence of surface waves on herding.

An experiment to examine the effects of surface waves on the herding of yellowfin sole, patterned after the experiments described in Somerton and Munro (2001), was conducted aboard the $56.7 \mathrm{~m}$ stern trawler FV Cape Flattery during 11-16 August 2016 in the EBS near $60^{\circ} 33^{\prime} \mathrm{N}$ and $170^{\circ} 29^{\prime} \mathrm{W}$. On each day of the experiment, 3 paired tows were completed according to all EBS survey operating protocols (Stauffer, 2004), except that for one tow of each pair, 27.4-m bridles were used, and for the other tow of the pair, 82.3-m bridles were used, instead of the standard $54.9-\mathrm{m}$ bridles. The tow order of each bridle length was alternated in successive pairs to help reduce the potential for a tow order effect. Although the tow direction of each pair could vary with wind and wave direction, tow direction within each pair was always identical. During each tow, net and door spread was measured to the nearest $0.1 \mathrm{~m}$ with an acoustic mensuration system (Marport Deep Sea Technologies Inc., Saint John's, Canada) and tow length was measured with GPS from the first to last bottom contact of the footrope, determined by using a BCS. Yellowfin sole were sorted from each catch and collectively weighed but not counted. Catch weight in each tow was later standardized by dividing by the swept area of the net (i.e., net width multiplied by tow length). Swell and wave heights were also estimated for each tow and, as in the previous experiment, were summed together and referred to as "wave height." However, unlike the earlier sea-state experiment, we did not have a heave recorder and therefore wave height was used as the descriptor of sea state. Over the $6 \mathrm{~d}$ of the experiment, 18 pairs of tows were completed.

Analysis of the herding data An index of the strength of herding for each pair of tows was calculated as the catch ratio (i.e., the standardized catch from the long bridle tow divided by that of the short bridle tow in each tow pair). Because the 2 bridle lengths result in a strong contrast in bridle contact area, any factor that 
reduces either the size of the bridle contact area or the effectiveness of herding within the area will have a greater impact on the catch from the longer bridle and should result in a decrease in catch ratio. Thus, to determine whether herding is influenced by wave height, we used linear modeling (function $\mathrm{lm}$ in $\mathrm{R}$ ) to examine whether the catch ratio was significantly related to wave height.

\section{Modeling the mechanism of wave influence on catch ratios of yellowfin sole}

We propose the following model to describe how the catch ratio could vary with wave height. Starting with the trawl catch model presented in Somerton et al. (2007), a trawl catch can be expressed as a function of trawl measurements (see Fig. 1B for definitions) and other variables:

$$
C=k_{\mathrm{n}}\left(w_{\mathrm{n}}+h\left(w_{\mathrm{on}}\right)\right) D L,
$$

where $C=$ catch in weight;

$w_{\mathrm{n}}=$ net path width;

$w_{\text {on }}=$ width of the path contacted by the bridle;

$D=$ fish density;

$L=$ tow length;

$k_{\mathrm{n}}=$ proportion of fish within the net path width that are captured; and

$h=$ proportion of fish within the bridle contact area that are herded into the net path.

However, to better describe how sea state may affect the catch, it is simpler to express the relationship in terms of the bridle lengths and the bridle angle of attack $(\alpha)$. To do this, $w_{\text {on }}$ is redefined as

$$
w_{\text {on }}=2 \sin (\alpha)\left(L_{\mathrm{bt}}-L_{\mathrm{off}}\right) \text {, }
$$

where $L_{\mathrm{bt}}=$ bridle length including the length of the tail chain extensions connecting the doors to the bridles. The tail chain extensions used in the herding experiment were $12 \mathrm{~m}$.

$L_{\text {off }}=$ distance between the door and the point along the bridle where bottom contact is maintained $50 \%$ of the time; and $\alpha=$ bridle angle of attack.

The angle of attack can be calculated for each tow as

$$
\alpha=\sin ^{-1}\left(\frac{w_{\mathrm{d}}-w_{\mathrm{n}}}{2 L_{\mathrm{bt}}}\right) \text {. }
$$

Assuming that $D$ and $k_{\mathrm{n}}$ are approximately constant for each pair of tows, then the catch ratio $(R)$ can be expressed as

$$
R=\frac{C^{\mathrm{l}}}{C^{\mathrm{s}}}=\frac{w_{\mathrm{n}}+h\left(2 \sin (\alpha)\left(L_{\mathrm{bt}}^{\mathrm{l}}-L_{\mathrm{off}}\right)\right)}{w_{\mathrm{n}}+h\left(2 \sin (\alpha)\left(L_{\mathrm{bt}}^{s}-L_{\mathrm{off}}\right)\right)}
$$

where the superscripts $l$ and $s$ represent the long and short bridles.

In this expression $C^{\mathrm{l}}, C^{\mathrm{s}}, w_{\mathrm{n}}, \alpha, L_{\mathrm{bt}}^{\mathrm{l}}$ and $L_{\mathrm{bt}}^{\mathrm{s}}$ are measured for every pair of tows, however $h$ and $L_{\text {off }}$ need to be estimated by using data from separate experiments. Estimates of these parameters are available from pre- vious studies of the survey trawl and its operation on yellowfin sole (Somerton and Munro, 2001); these are $h=0.58$ and $L_{\text {off }}=36 \mathrm{~m}$. However, the estimate of $L_{\text {off }}$ is available only for standard length bridles, not the 2 lengths used in our herding study. Consequently, as in the original study, we assumed $L_{\text {off }}$ is constant at all experimental bridle lengths, but only at zero wave height. At wave heights $>0$, we assumed that $L_{\text {off }}$ increases linearly with wave height, but at a rate that differs between bridle lengths. With these changes the wave-height-dependent herding model becomes

$$
R=\frac{C^{\mathrm{l}}}{C^{\mathrm{s}}}=\frac{w_{\mathrm{n}}+0.58\left(2 \sin (\alpha)\left(L_{\mathrm{bt}}^{\mathrm{l}}-\left(36+k^{\mathrm{l} H}\right)\right)\right)}{w_{\mathrm{n}}+0.58\left(2 \sin (\alpha)\left(L_{\mathrm{bt}}^{\mathrm{s}}-\left(36+k^{\mathrm{s}} H\right)\right)\right)},
$$

where $H=$ the estimated wave height; and

$k^{\mathrm{l}}, k^{\mathrm{s}}=$ coefficients regulating the influence of wave height on $L_{\text {off }}$ for the long and short bridles.

With this formulation, we are assuming that the only influence of wave height on herding is that of decreasing the length of the bridle in contact with the bottom, which happens differently for the long and short bridles. The choice in the form of the wave height effect was, in part, guided by the results of the sea state and trawl performance study, which will be considered later. Note that when $H=0, L_{\text {off }}$ becomes identical to the experimentally measured value and is identical for long and short bridle lengths. Therefore, the model has 2 unknown parameters; that is, $k^{1}$ and $k^{\mathrm{s}}$. To estimate these parameters we considered the right side of the above equation as a predicted value of the catch ratio and minimized the sum of the squared differences between the observed and predicted catch ratios over the 18 paired tows, using nonlinear minimization ( $\mathrm{R}$ function nlm).

\section{Variation in survey abundances of yellowfin sole with wave height}

The abundance of yellowfin sole in the EBS survey area is estimated annually with the EBS survey by using the swept-area method applied to each of the 356 stations located at the centers of a rectangular sampling grid (Conner and Lauth, 2016). Annual abundance is estimated by multiplying the estimates of local density (i.e., catch/trawl swept area) by the area of each grid square and then summing over all grid squares. A variety of environmental parameters are also measured at each sampling site, including swell and wave heights estimated by the vessel captain, which again were summed and referred to as wave height. Although the survey time series began in 1982, the wave height data have only been available since 2005. For each year of data, wave height was averaged over all sampling sites where yellowfin sole were caught.

To determine whether the abundance estimates from the yellowfin sole survey were influenced by variation in wave height, perhaps because wave height influenced trawl sampling efficiency, we modeled the survey abundance estimates as a linear function of mean 


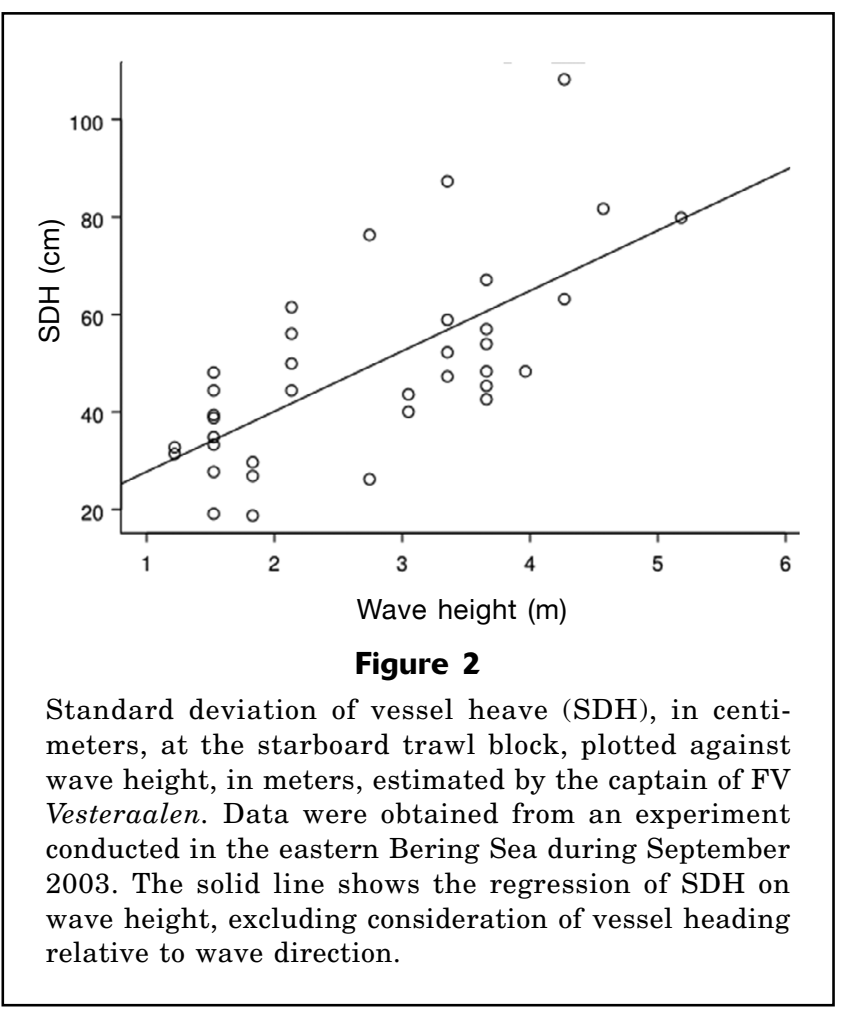

wave height ( $\mathrm{R}$ function $\mathrm{lm}$ ) and tested the significance of the slope, using standard methods. However, it is possible that factors, such as a temporal change in population structure, could influence this relationship. Therefore, to better isolate interannual changes due to waves from more gradual changes, we calculated the deviations between the survey abundance estimates and the abundance estimates produced by the yellowfin sole stock assessment model (Wilderbuer et al. ${ }^{1}$ ), then modeled the deviations as a linear function of mean wave height. The estimates of abundance from the models we used are slightly different from those reported in Wilderbuer et al. ${ }^{1}$ because the version of the model used for stock assessment included an environmental correlate (mean bottom temperature). Because we were examining the influence of another environmental correlate, we fitted the model without the temperature effect to produce the model estimates of survey abundances used in our analysis.

\section{Results}

\section{Vessel motion and wave height}

Vessel motion, expressed as the SDH, increased significantly with the estimated wave height (Fig. 2, Table 1). However, SDH was not significantly related to either the numeric or the binary measure of the alignment of vessel heading and wave direction.

\section{Table 1}

The relationship between the standard deviation of vessel heave at the trawl block with the 3 predictor variables from results of an experiment conducted in the eastern Bering Sea during September 2003. The predictor variables are 1) wave height (summed values of wave and swell heights estimated by the vessel captain), 2) alignment (alignment of vessel course and wave direction, i.e., absolute value of the cosine of the angle between the 2 directions) and 3 ) relative direction (vessel course either away from, $\pm 180^{\circ}$, or into the direction of wave travel).

\begin{tabular}{lrr}
\hline & Coefficient & $P$-value \\
\hline Intercept & 14.10 & 0.071 \\
Wave height & 11.98 & $<0.001$ \\
Alignment & -2.86 & 0.259 \\
Relative direction & 0.07 & 0.500 \\
& & \\
\hline
\end{tabular}

\section{Bridle and footrope distances off bottom}

Off-bottom distance measurements along the lower bridles and footrope oscillated with a period nearly identical to that of vessel motion. For example, on one haul, which had a wave height of $5.3 \mathrm{~m}$, the heave oscillation period ( $5.13 \mathrm{~s}$ ) was nearly identical to that for the periods measured at all trawl positions, both along the bridles $(50 \mathrm{~m}, 5.16 \mathrm{~s} ; 40 \mathrm{~m}, 5.12 \mathrm{~s} ; 25 \mathrm{~m}, 5.12 \mathrm{~s})$ and along the footrope (wing, $5.16 \mathrm{~s}$; corner, $5.16 \mathrm{~s}$; center, $5.16 \mathrm{~s}$ ). At low levels of SDH, however, spectral peaks were harder to identify, and the variability among positions increased. This finding indicates that, at least for relatively high waves, vessel motion is detectable throughout the trawl and substantiates the notion that surface waves influence trawl performance.

The magnitude of the trawl oscillatory movement, expressed as the standard deviation of off-bottom distance, increased significantly with SDH at all trawl positions, except at the wings. The magnitude of the increase (slope of the regression line) varied with position (Fig. 3, Table 2). The smallest increase in SDH occurs at the wings, consistent with the design of the survey trawl that produces the maximum bottom contact, and presumably strongest downward force at the wing tips. Away from the point of maximum bottom contact, both forward along the bridles and aft along the footrope, the standard deviation of off-bottom distance increases as the constraints on vertical motion, such as tension and bottom contact, lessen. At the $50-\mathrm{m}$ bridle position, where the bridle rarely contacts the bottom, the oscillations were the largest (Table 2).

The mean distance off bottom also varied among trawl positions; however, its increase with SDH was only significant at the $40-\mathrm{m}$ bridle position (Fig. 4, Table 3 ). At the wing and the 25-m bridle positions, the downward forces keep the mean off-bottom distance 


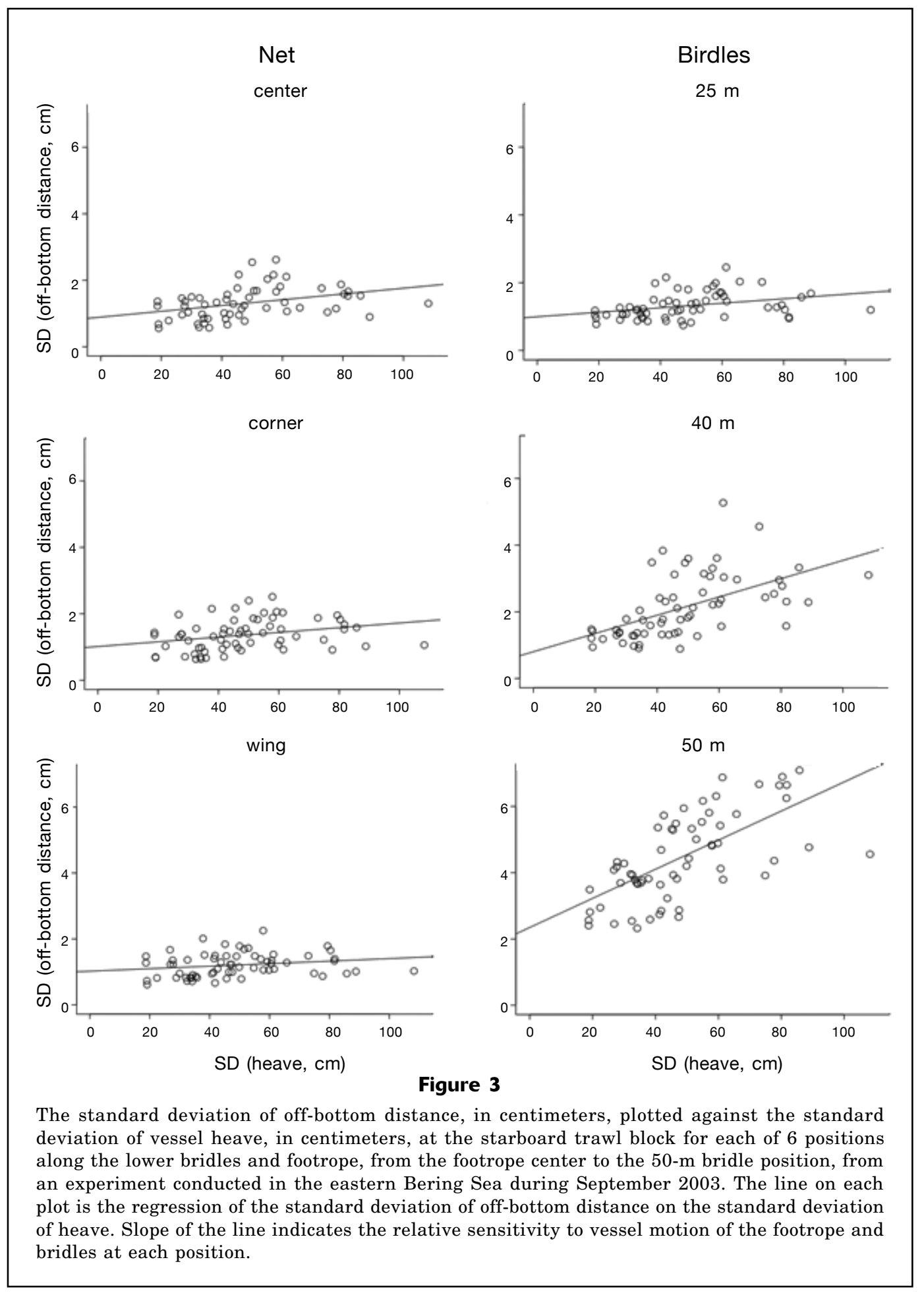

relatively insensitive to changes in $\mathrm{SDH}$; however at the $40-\mathrm{m}$ bridle position the constraints on vertical motion are less and the mean off-bottom distance increases with wave height. At the $50-\mathrm{m}$ bridle position, the vertical oscillations are apparently unconstrained by the bottom, so that the mean off-bottom distance is independent of SDH.
One consequence of the progressive sensitivity of mean off-bottom distance to SDH with increasing distance from the wing tips (at least out to $40 \mathrm{~m}$ ) is that the length of the bridle in contact with the bottom must decrease with SDH. To show this, we evaluated equations predicting off-bottom distance (Table 3) at the wing, and at the $25 \mathrm{~m}, 40 \mathrm{~m}$, and $50 \mathrm{~m}$ bridle posi- 


\section{Table 2}

Slope, intercept, and $P$-value for linear regressions of vertical motion, expressed as the standard deviation of off-bottom distance (in centimeters) at various positions along the lower bridles and footrope, against vessel motion, expressed as standard deviation of vessel heave at the trawl block from an experiment conducted in the eastern Bering Sea during September 2003.

\begin{tabular}{lccc}
\hline Position & Intercept & Slope & $P$-value \\
\hline Center & 0.893 & 0.0087 & 0.005 \\
Corner & 1.016 & 0.0071 & 0.019 \\
Wing & 1.022 & 0.0038 & 0.103 \\
Bridle-25 m & 0.997 & 0.0066 & 0.0073 \\
Bridle-40 m & 0.803 & 0.0274 & $<0.001$ \\
Bridle-50 m & 2.349 & 0.0439 & $<0.001$ \\
& & & \\
\end{tabular}

tions at 5 levels of $\operatorname{SDH}(0,20,40,60,80 \mathrm{~cm})$ and then plotted the predicted off-bottom distances as a function of SDH (Fig. 5). Comparing the off-bottom distances in this way emphasizes that, in terms of a mean response, the primary influence of SDH on off-bottom distance occurs in the region between the 25 - and $40-\mathrm{m}$ positions, which is near the point where the bridle leaves the bottom in calm conditions ( $31 \mathrm{~m}$ from the wing; Somerton and Munro, 2001). If a value of off-bottom distance is specified as a critical value for herding (e.g., in Fig. 5 a value of $2.5 \mathrm{~cm}$ is used), then as SDH increases, the bridle position at the critical value of offbottom distance moves toward the wing tip, reducing the area exposed to herding.

Although the change in the mean off-bottom distance at the center and corner positions on the footrope are not significant, the slopes of the regressions are nearly as large as those at the $40-\mathrm{m}$ bridle positions (Table 3 ), but there is more haul-to-haul variability. This relationship indicates that the oscillations are also likely to impact escapement along the footrope.

\section{Influence of wave height on the herding of yellowfin sole}

In the yellowfin sole herding experiment, the catch ratio declined significantly with increasing wave height ( $R=1.96-(0.51 \times$ wave height), $P=0.038$, coefficient of determination $\left[r^{2}\right]=0.24$; Fig. 6 ). Because the catch ratio was based on pairs of tows taken near each other, in the same direction, and in quick succession, essentially all influences on catch were kept constant, except that of bridle length. Therefore, the decrease in catch ratio with increasing wave height indicates that herding was decreased.

Our hypothesized model expressing the influence of wave height on catch ratio is shown below with the estimated values of $k^{1}$ and $k^{\mathrm{s}}$ :

$$
R=\frac{w_{\mathrm{n}}+0.58\left(2 \sin (\alpha)\left(L_{\mathrm{bt}}^{1}-(36+2.29 H)\right)\right.}{w_{\mathrm{n}}+0.58\left(2 \sin (\alpha)\left(L_{\mathrm{bt}}^{\mathrm{S}}-(36+0.042 H)\right)\right.} .
$$

The estimated value of $k^{1}$ is considerably larger than $k^{\mathrm{s}}$, confirming the notion that the impact of wave height would be stronger for the long bridles. However, the fit of the model to the catch ratios was poorer $\left(r^{2}=0.12\right)$ than the fit of the wave height data itself to the catch ratios $\left(r^{2}=0.24\right)$. This result indicates that either the model was incorrectly specified, perhaps lacking other important factors influenced by wave height, or that the fixed parameter estimates (i.e., $h$ and $L_{\text {off }}$ ) obtained from previous studies were biased.

Influence of wave height on annual estimates of yellowfin sole abundance

The biomass of yellowfin sole estimated by the EBS bottom trawl survey, during the period 2005-2016, declined significantly with an increase in the mean wave height (biomass $=3.37-(0.67 \times$ wave height $), P=0.028$, $r^{2}=0.40$; Fig. 7). The deviations between the survey biomass estimates and those produced by the yellowfin sole stock assessment model, during the same time period, also declined significantly with an increase in the mean wave height (deviation $=1.11-(0.19 \times$ wave height), $P=0.044, r^{2}=0.35$; Fig. 7). This result indicates that wave height, perhaps through its apparent effect on herding, may produce a detectable bias in the annual estimates of yellowfin sole abundance in the EBS.

\section{Discussion}

\section{Wave height and vessel motion}

It is clear that wave height influences vessel motion. This was shown by the strong correlation of SDH with estimated wave height. However, SDH was insensitive to vessel heading relative to wave direction, which is counterintuitive to most observers standing on the deck of a vessel. An alternate measure of vessel motion proposed by Politis et al. (2012) divides heave by time to create a measure of vertical speed, which is sensitive to vessel heading relative to the waves. We chose $\mathrm{SDH}$ as a measure of vessel motion because it is consistent with the subjective estimates of wave heights now provided by vessel captains and which are the basis of our time series of sea states encountered during trawl surveys.

An objective, repeatable, measure of wave height obtained with a vessel heave sensor is definitely preferred to the subjective estimates now provided by vessel captains. Although heave sensors are nearly always included in the instrument suite on fishery research vessels, all NOAA bottom trawl surveys conducted by chartered fishing vessels along the U.S. West Coast do not use heave sensors (Stauffer, 2004); therefore the only available information on sea-state is the wave and swell heights estimated by the vessel captains. Such estimates are inadequate because they are subjective, likely to vary among vessel captains, and do not capture variability in vessel motion introduced by factors 


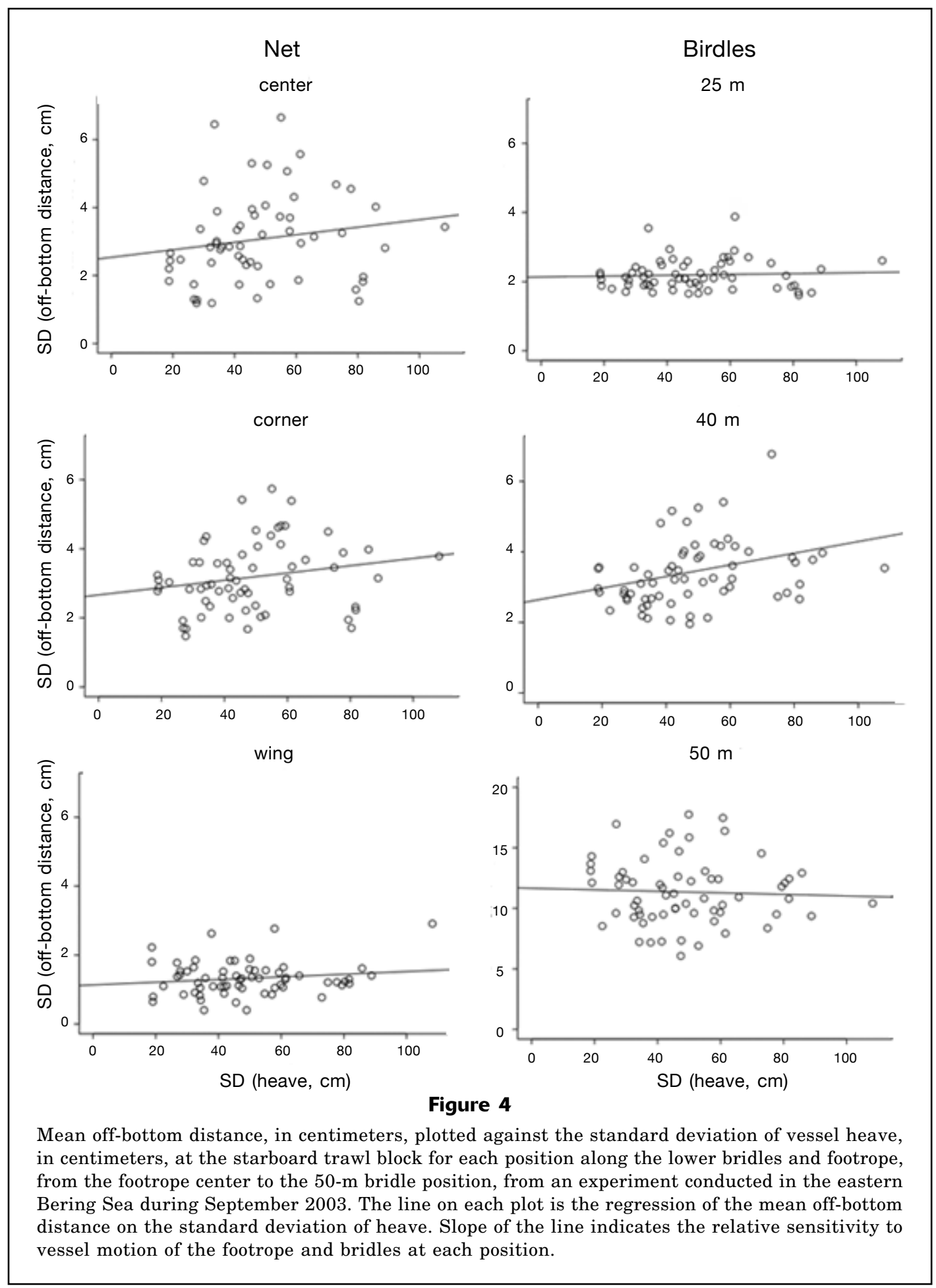

such as vessel size and trawling procedures. As in previous studies of the influence of sea-state on bottom trawl surveys (Stewart et al., 2010; Politis et al., 2012), we emphasize the need to measure vessel motion directly on all trawl survey vessels.

The coherence between the vertical oscillations of the vessel and the vertical oscillations at all measured positions along the bridles and footrope of the trawl indicate that, at least in high waves, vessel motion is transmitted down the warps and throughout the trawl. O'Neill et al. (2003) and Politis et al. (2012) used similar methods to ours and obtained similar results. For bottom trawl surveys, however, the important question is how these oscillations influence sampling efficiency. 


\section{Table 3}

Slope, intercept, and $P$-value for linear regressions of the mean distance off-bottom, in centimeters at various positions along the lower bridles and footrope, against vessel motion expressed as the standard deviation of vessel heave at the trawl block from an experiment conducted in the eastern Bering Sea during September 2003.

\begin{tabular}{lrrr}
\hline Position & Intercept & Slope & $P$-value \\
\hline Center & 2.537 & 0.0111 & 0.197 \\
Corner & 2.664 & 0.0106 & 0.101 \\
Wing & 1.136 & 0.0039 & 0.223 \\
Bridle-25 m & 2.133 & 0.0013 & 0.665 \\
Bridle-40 m & 2.642 & 0.0165 & 0.017 \\
Bridle-50 m & 11.661 & -0.0063 & 0.722 \\
& & & \\
\hline
\end{tabular}

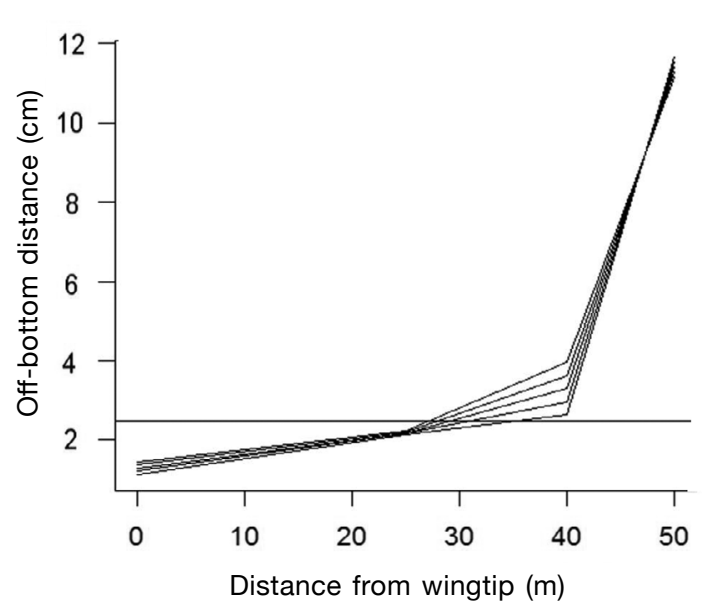

Figure 5

Predicted off-bottom distance at the 0-, 25-, 40-, and $50-\mathrm{m}$ positions on the lower bridles by using the parameters in Table 3. Predictions were made at 5 levels of vessel motion (standard deviation of vessel heave $[\mathrm{SDH}]$ at the starboard trawl block: $0,20,40,60,80 \mathrm{~cm}$ ) spanning the values observed during the experiment conducted in August 2016 to examine the effect of wave height on herding of yellowfin sole (Limanda aspera). In the region between 25 and $40 \mathrm{~m}$, the top line corresponds with an SDH of $80 \mathrm{~cm}$, and the bottom- line corresponds with an SDH of 0 . The horizontal line represents a hypothetical reference level of off-bottom distance, $2.5 \mathrm{~cm}$, above which the bridle no longer elicits herding of yellowfin sole. As SDH increases, the point along the bridle where herding ceases (i.e., the intersection point of the horizontal and diagonal lines) moves progressively toward the wings.

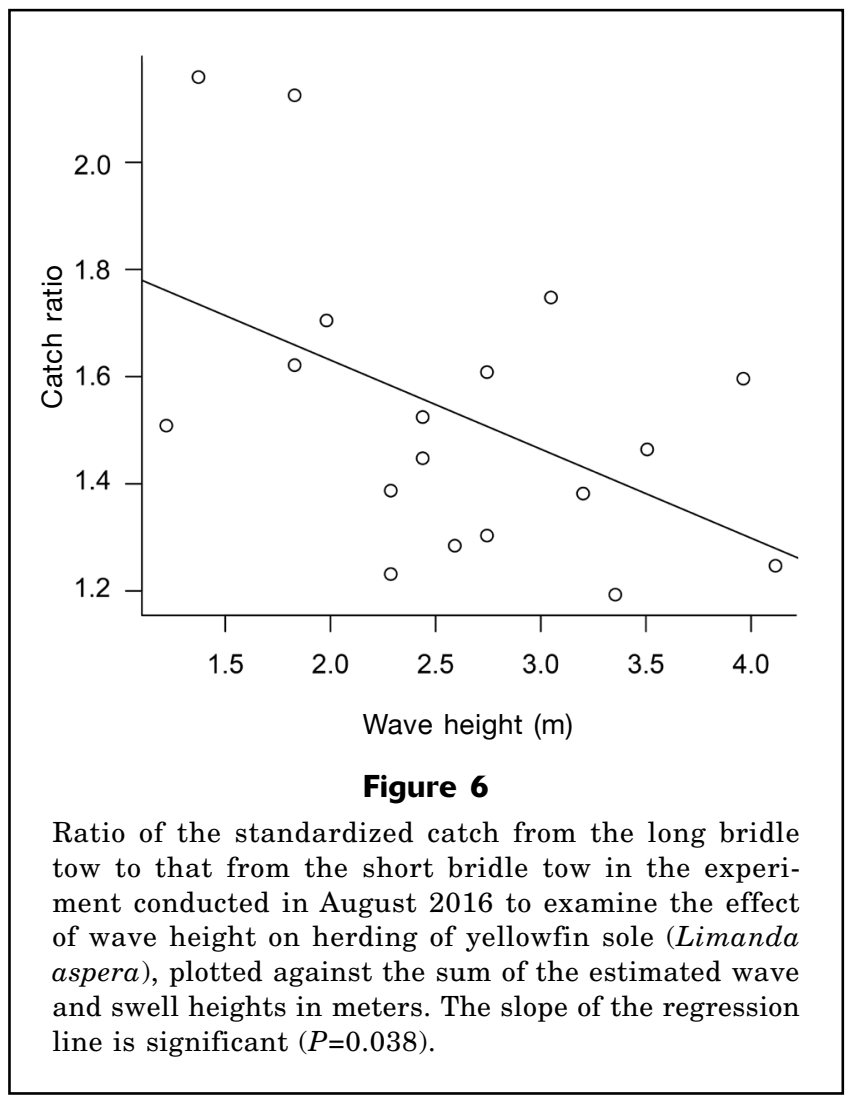

For the 83-112 Eastern trawl, one important effect of the oscillations is that they result in an increase in the mean off-bottom distance at the bridle position that is most influential in determining the size of the bridle contact area. Prior studies of herding by the survey trawl conducted in calm conditions indicate that the off-bottom distance of the lower bridle increases forward of the wing tips and at $\sim 31 \mathrm{~m}$ reaches an offbottom distance sufficiently large that the bridle no longer elicits herding behavior of flatfish (Somerton and Munro, 2001). Our study on the change in mean off-bottom distance with SDH along the lower bridles indicates that at $25 \mathrm{~m}$ the downward forces are sufficient to inhibit a change in off-bottom distance with increasing $\mathrm{SDH}$; however at $40 \mathrm{~m}$ the change is the highest of all measured positions. As a consequence, the length of the bridle in contact with the bottom, and the size of the area exposed to herding stimuli, will decrease with increasing SDH (Fig. 5).

Another likely effect of SDH is on escapement under the footrope. Studies show that the central portion of the footrope is the aggregation point of herded flatfish and where most escapement occurs (Main and Sangster, 1981). In addition, escapement of flatfishes under the footrope of the survey trawl has been shown to increase as the off-bottom distance increases at the center of the footrope (Weinberg et al., 2002). Consequently, any factor that increases footrope off-bottom distance should increase escapement, and although not 

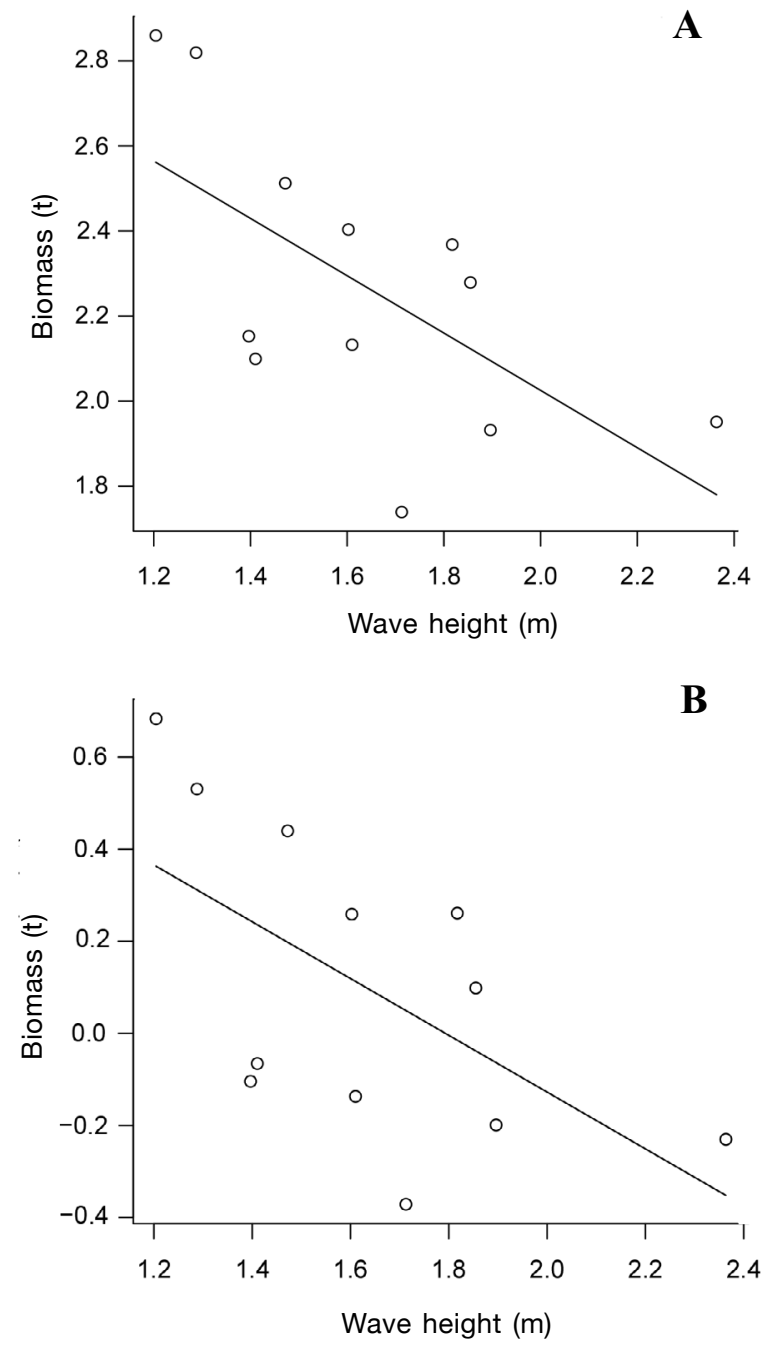

Figure 7

(A) Swept-area biomass, in metric tons (t), of yellowfin sole (Limanda aspera) estimated by the bottom trawl survey conducted in the eastern Bering Sea by the National Marine Fisheries Service during 2005-2016, plotted against the sum of the estimated wave and swell heights, in meters, averaged over all stations where yellowfin sole were caught. The slope of this regression line is significant $(P=0.028)$. (B) Deviations between the swept-area biomass estimates and the biomass predicted by the stock assessment model for yellowfin sole in relation to wave height. The slope of the regression line is significant $(P=0.044)$

significant, the increase in the off-bottom distance at the center and corner portions of the footrope indicate that escapement is likely also affected by sea state.

Besides their effect of changing mean distance offbottom, the vertical oscillations undoubtedly have a pronounced effect on fish escapement and herding be- haviors. The studies of both O'Neill et al. (2003) and Politis et al. (2012) show that the oscillations we measured in terms of off-bottom distance also produce oscillations in trawl speed. Such oscillations were shown to be the principal mechanism for the increase in escapement from the codend mesh with increased seastate, both by changing mesh geometry and by altering fish behavior (O'Neill et al., 2003). However, we have no direct evidence of how either the vertical oscillations of the footrope and bridles on the survey trawl or the likely oscillations in speed influence the escapement or herding behavior of yellowfin sole.

\section{Influence of wave height on the herding of yellowfin sole}

Based on the results of the yellowfin sole herding experiment, the ratio of the standardized catches from long and short bridle tows clearly declined with increasing wave height. Because the paired design of the bridle experiment was intended to minimize all influences other than bridle length, the decline in catch ratio shows that sampling efficiency declined with increasing wave height. We suspect this result is due to diminished herding.

We proposed a model to predict how catch ratio could vary as a function of wave height to explore possible mechanisms to explain the observed change in catch ratio. This model focuses on the change in bridle contact area with increasing $\mathrm{SDH}$ described earlier. Although the model does predict a decrease in catch ratio with increasing $\mathrm{SDH}$, it explains only half of the variability in catch ratio that is explained by a simple linear regression on SDH. One reason for the poor fit is that the model considers herding to be a product of the bridle contact area and the efficiency of herding within this area. Therefore, parameters affecting the bridle area $\left(L_{\text {off }}\right)$ are confounded with parameters affecting the efficiency of herding $(h)$ within the bridle contact area, and a priori estimates of at least one is needed to obtain a tractable solution. The values we used for these two parameters were obtained from an experiment conducted in relatively calm conditions (Somerton and Munro, 2001) and may well be biased when applied to rougher sea-state conditions. Furthermore, the estimate of $L_{\text {off }}$ was obtained from an experiment in which only standard length bridles were considered (Somerton and Munro, 2001). We applied this value to bridles both longer and shorter than the standard length with some hesitancy, although in a similar study in which off-bottom distances were measured along 3 lengths of bridle on a bottom trawl, this value was found to be reasonable (Somerton, 2003). In addition to these issues, we were concerned that the herding process during high waves may be fundamentally different from that in calm water. For example, when the bridle experiences increased tension and lifts off the bottom, we assumed in our model, that the effect is to momentarily shorten the length of the bridle in contact with the bottom and thereby decrease the area of herding. However, the vertical motion itself 
may create a greater herding stimulus than a similar length of bridle in calm water. If so, then the efficiency of herding within the bridle contact area, which was assumed to be constant, would also be influenced by wave height. Further research is needed to better define these parameters and determine how they might change at higher sea states.

\section{Estimated abundance of yellowfin sole and its relation to wave height}

The abundance of yellowfin sole estimated by the annual bottom trawl survey clearly declines with an increase in mean wave height (Fig. 7) - a finding that is consistent with wave height effects reported for the NOAA West Coast bottom trawl survey (Stewart et al., 2010). In addition, the deviations between the survey estimates and assessment model estimates of abundance also decline with an increase in mean wave height (Fig. 7). The question is whether these associations establish causation. We have shown that increased wave height results in a reduction in the bridle contact area, which should reduce the herding of flatfish. We also confirmed this notion by providing evidence that increased wave height reduces the sampling efficiency of yellowfin sole, presumably owing to the reduction in herding. However, a decrease in herding by itself may not exert a sufficiently strong effect to account for the observed decline in estimated yellowfin sole biomass because during normal survey conditions only $\sim 30 \%$ of a flatfish catch comprises herded fish (Somerton et al., 2007). However, the potential effects of wave height on sampling efficiency could be much larger if escapement under the footrope is considered.

Although our experimental evidence showed that the mean off-bottom distance at all points on the footrope did not increase significantly with $\mathrm{SDH}$, the magnitude of the change was still strong enough to potentially allow greater escapement. Coupled with both the oscillations in off-bottom distance and, likely, trawl speed, we suspect that footrope escapement increases with $\mathrm{SDH}$, but we have no experimental evidence to prove this.

Exactly how the vertical and horizontal oscillatory motion of the footrope and bridles influences fish behavior is unknown. However, the study of O'Neill et al. (2003) on codend mesh escapement has shown that oscillations in trawl speed produce changes in fish behavior, as well as changes in net geometry. Consequently, footrope escapement and bridle herding may be quite different in an elevated sea state from what has been reported for relatively calm water (Somerton et al., 2007) and this difference may be the primary reason why we obtained such a poor fit of our model to the experimental catch ratio data.

Even with the potential for increased footrope escapement to compound the apparent influence wave height has on sampling efficiency of the survey trawl, the observed decrease in yellowfin sole biomass estimates with increased wave height may also reflect other influences. Wilderbuer et al. ${ }^{1}$, in a stock assessment model for EBS yellowfin sole, determined that the trawl survey catchability function is temperature dependent and that the estimated stock abundance declines at colder temperatures. Two hypotheses were proposed for this: 1) sampling efficiency of the survey trawl is temperature dependent (i.e., yellowfin sole herd less or escape more in cold water) and 2) availability of this species to the survey is temperature dependent (i.e., more yellowfin sole remain in their shallow spawning areas, which are outside the survey area, during colder years). To complicate these hypotheses further, annual mean wave height and bottom temperatures in yellowfin sole areas are negatively correlated $\left(\mathrm{Nichol}^{3}\right)$, and therefore perhaps both sampling efficiency and availability are involved. Regardless of which mechanism is ultimately responsible for the correlation between yellowfin sole abundance and wave height, the inclusion of either variable in the survey catchability function used in the yellowfin sole assessment model of the National Marine Fisheries Service will have a significant effect on the estimates of total allowable catch for this species. Therefore further research to clarify this issue is critically needed.

\section{Acknowledgments}

We thank B. Lauth, D. Nichol, and W. Palsson for reviewing the manuscript, D. Nichol for providing the EBS survey wave height and yellowfin catch data, and the captains and crew of the FV Vesteraalen and FV Cape Flattery for their help and expertise during the experiments. This research was funded, in part, by NOAA, National Marine Fisheries Service, Office of Sustainable Fisheries from their National Catch Share and Magnuson-Steven Act Implementation Funds.

\section{Literature cited}

Conner, J., and R. R. Lauth.

2016. Results of the 2013 eastern Bering Sea continental shelf bottom trawl survey of groundfish and invertebrate resources. NOAA Tech. Memo. NMFS-AFSC-331, 153 p. Tech. Memo.

Dickson, W.

1993. Estimation of the capture efficiency of trawl gear. I: Development of a theoretical model. Fish. Res. 16:239-253. Article

Engås, A., and O. R. Godø.

1989. The effect of different sweep lengths on the length composition of bottom-sampling trawl catches. ICES J. Mar. Sci. 45: 263-268. Article

Kimura, D. K., and D. A. Somerton.

2006. Review of statistical aspects of survey sampling for marine fisheries. Rev. Fish. Sci. 14:245-283. Article

\footnotetext{
${ }^{3}$ Nichol, D. 2016. Personal commun. Resour. Assess. Conserv. Eng. Div., Alaska Fish. Sci. Cent., Natl. Mar. Fish. Serv., 7600 Sand Point Way NE, Bldg. 4, Seattle, WA 981156349 .
} 
Main, J., and G. I. Sangster.

1981. A study of the fish capture process in a bottom trawl by direct observations from a towed underwater vehicle. Scott. Fish. Res. Rep. 23, 23 p.

Munro, P. T., and D. A. Somerton.

2002. Estimating net efficiency of a survey trawl for flatfishes. Fish. Res. 55:267-279. Article

O’Neill, F. G., S. J. McKay, J. N. Ward, A. Strickland, R. J. Kynoch, and A. F Zuur

2003. An investigation of the relationship between sea state induced vessel motion and cod-end selection. Fish. Res. 60:107-130. Article

Politis, P. J., J. T. DeAlteris, R. W. Brown, and A. T. Morrison III.

2012. Effects of sea-state on the physical performance of a survey bottom trawl. Fish. Res. 123:26-36. Article

$\mathrm{R}$ Development Core Team.

2004. R: a language and environment for statistical computing. R Foundation for Statistical Computing, Vienna, Austria. [Available from website, accessed October 2004.]

Somerton, D. A.

2003. Bridle efficiency of a survey trawl for flatfish: measuring the length of the bridles in contact with the bottom. Fish. Res. 60:273-279. Article
Somerton, D. A., and P. T. Munro.

2001. Bridle efficiency of a survey trawl for flatfish. Fish. Bull. 99:641-652.

Somerton, D. A., P. T. Munro, and K. L. Weinberg.

2007. Whole-gear efficiency of a benthic survey trawl for flatfish. Fish. Bull. 105:278-291.

Stauffer, G. (compiler).

2004. NOAA protocols for groundfish bottom trawl surveys of the nation's fishery resources. NOAA Tech. Memo. NMFS-SPO-65, 205 p.

Stewart, I. J., A. A. Keller, E. L. Fruh, V. H. Simon, and B. H. Horness.

2010. Throwing in the towel: when do adverse conditions dictate a weather day during a bottom trawl survey? Fish. Res. 102:130-140. Article

Venables, W. N., and B. D. Ripley.

1994. Modern applied statistics with S-plus, 462 p. Springer-Verlag, New York.

Weinberg, K. L., and D. A. Somerton.

2006. Variation in trawl geometry due to unequal warp length. Fish. Bull. 104:21-34.

Weinberg, K. L., D. A. Somerton, and P. T. Munro.

2002. The effect of trawl speed on the footrope capture efficiency of a survey trawl. Fish. Res. 58:303-313. Article 